\title{
An alternative approach to provisions of the Network Code on blocking HVDC LCC systems during short-circuits in AC network
}

\author{
Mateusz Szablicki ${ }^{1,2^{*}}$, Piotr Rzepka ${ }^{1,2}$, Adrian Halinka ${ }^{1}$, and Rafat Czapaj ${ }^{2}$ \\ ${ }^{1}$ Silesian University of Technology, Institute of Power Systems and Control, Gliwice, Poland \\ ${ }^{2}$ PSE Innovations Ltd., Warsaw, Poland
}

\begin{abstract}
The Network Code for HVDC systems introduces a requirement for such systems to remain in operation in an AC network during short-circuits. This requirement (among others) is determined by a time curve of a minimum voltage in HVDC connection point. The HVDC system is not allowed to be turned-off while the voltage value exceeds the values of the curve, however the HVDC system in LCC technology does not meet this requirement. The Network Code introduces the possibility of blocking the LCC systems. After the LCC system is blocked it stops transmitting the power, which prevents the LCC system from being turned off during a short-circuit in the network but results in a lack of power exchange between the network and the LCC system. Therefore, the authors developed a proposal to limit the power level being transmitted by the LCC system, thus there is no necessity to block the LCC system operation. The simulation research carried out clearly indicate the validity of this idea. In addition, the authors presented the concept of an automation system that adaptively adjusts the scale of the LCC system power level reduction to change the network operating conditions during a short-circuit in the network. The operation of this automation system is presented for the practical LCC system model installed in the Polish Power System.
\end{abstract}

\section{Background}

High Voltage Direct Current systems (HVDC) are increasingly used in Power Systems (PS). They enable power exchange between non-synchronous PSs, power transmission over long distances, power transmission through the sea, connection of offshore wind farms to PSs, etc. HVDCs are the subject to many national and international requirements. For the HVDC being connected to the pan-European PS, the European Union Commission established in 2016 a dedicated network code [1] (NC HVDC).

The NC HVDC is a set of requirements defining the desired HVDC capabilities. The NC HVDC defines among others expected HVDC behavior during short-circuits in the AC power network.

\footnotetext{
*Corresponding author: mateusz.szablicki@polsl.pl
} 


\section{Expected HVDC behavior during short-circuits in the AC network}

The NC HVDC introduces the requirement to remain HVDC in operation during shortcircuits in the AC network. This ability is determined by dedicated voltage waveform profile in accordance with article 25 of the NC HVDC. This profile refers to the minimum voltage at the HVDC connection point. The shape of this profile is shown in Figure 1. This is a proposal to implement NC HVDC for the Polish PS.

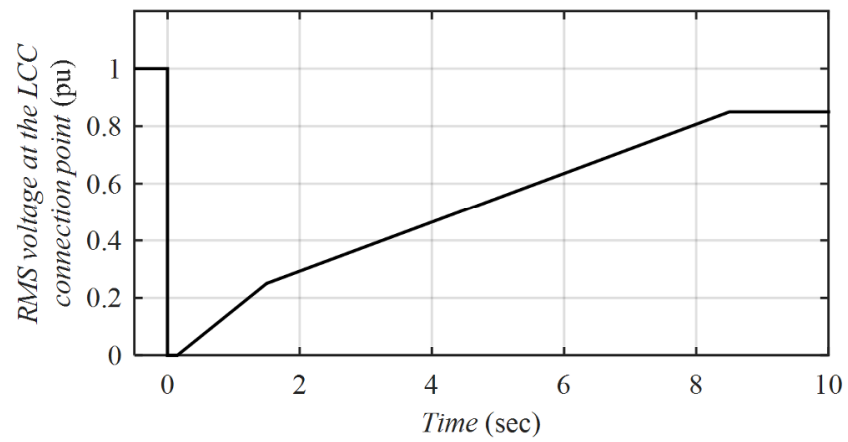

Fig. 1. The lower limit of the required HVDC voltage operating area during a short-circuit in the AC network, proposed for the Polish PS (based on [2]).

According to Figure 1, when the phase-to-phase voltage at the HVDC connection point is above the profile, the HVDC should not be turned off. The HVDC must be adapted to remain in operation. The possibility of achieving this expected ability is confirmed by the simulation results in [3-6].

However, HVDC implemented in Line Commutation Converters (LCC) does not meet this requirement. During short-circuits in the AC network, when the voltage value at the connection point decreases, there may commutation failures occur. A commutation failure is an undesirable situation in which another thyristor will be activated in the bridge of the converter system, although the commutation of the previously conducting thyristors has not yet been completed. This leads to a short-circuit. The phenomenon of the commutation failure is described in detail in [7-9].

Commutation problems in the LCC can continue until the AC network disturbance interruption the and the voltage increase to the nominal level. This is shown in Figure 2. The Figure 2 shows a short-circuit in the AC network, which was accompanied by a decrease in the RMS voltage value of one phase in the HVDC inverter station to 0.8 pu of the rated voltage.
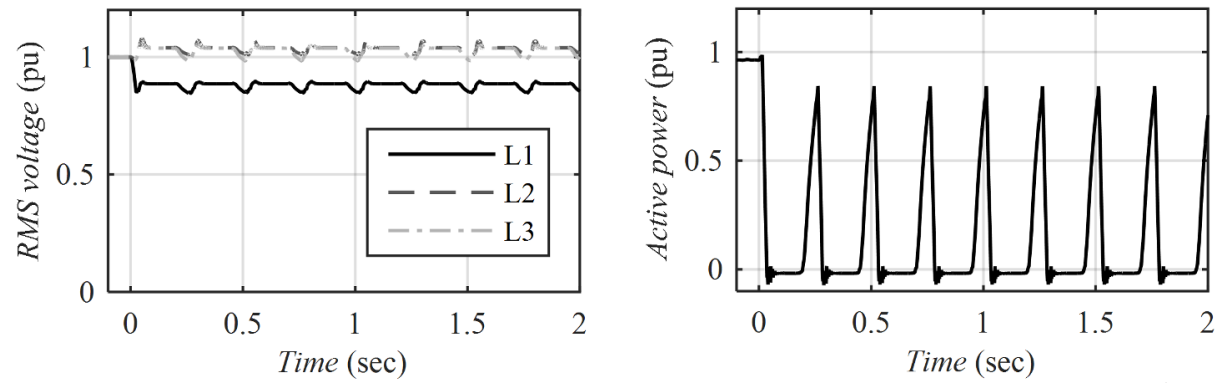

Fig. 2. The voltage in the inverter station and the power transmitted by the LCC during a short-circuit occurrence in the AC network (the short-circuit started in 0 second) [10]. 
Multiple commutation failures may force the LCC to be turned off. As a result, it worsens the security and stability of PS operation which are connected through a certain LCC. Therefore, the LCC blocking option was introduced in the NC HVDC (article 25, paragraph 4, NC HVDC). The undervoltage criterion is used as a blocking criterion - when the voltage value decreases at the LCC connection point below the blocking voltage, the LCC stops transmitting power, while maintaining connection with the PS. However, this results in a lack of power exchange between the PS and the LCC. Therefore, the authors have developed an alternative proposal. Instead of blocking the LCC, it is proposed to temporarily limit the level of power transmitted by the LCC. Then, power transmission through the LCC will be maintained, which creates better conditions for LCC cooperation with PS. Defining the concept of an automation system that will reduce LCC power after detecting a short-circuit in the AC network requires recognition of LCC systems' behavior for such disturbances.

\section{Simulation tests for LCC systems during short-circuits in the AC network}

One of the causes of commutation problems in LCC are short-circuits in the AC network, in the vicinity of LCC. The most dangerous short-circuits are short-circuits that cause significant voltage asymmetry at the LCC connection point. These are mainly single-phase short-circuits and especially single-phase Automatic Reclosing in Lines (ARL) connected to the LCC [9, 11-13]. Usually, such events are accompanied by unwanted multiple commutation failures.

This conclusion is the result of a retrospective analysis of the authors made for the SwePol Link. The SwePol Link is an HVDC LCC system connecting Poland and Sweden. It has a rated power of $600 \mathrm{MW}$. In Poland, it is connected to the $400 \mathrm{kV}$ power grid. It includes a $254 \mathrm{~km}$ long cable line (including an undersea section in the Baltic Sea) and a converter stations in Słupsk and Stärnö. In the years 2000 - 2013, commutation failures in the SwePol Link occurred over 200 times. The authors have analyzed them in detail. Their results constituted the basis for determining the simulation scenarios for this publication.

In order to carry out the simulations, a dynamic LCC model was developed. The SwePol Link was used as a case study. The model is based on the LCC reference model implemented in MATLAB Simulink software. It is presented in a simplified way in Figure 3. In the developed SwePol Link model, one can extract a rectifier part and an inverter part as well as a physical layer and a control layer. The most important components of the model in the physical layer are: converter transformer, 12-pulse thyristor converter, compensation and filtering systems of the AC part and elements of the main and return path of the DC part with smoothing chokes (reactors) and capacitor bank. The most important components of the model in the control layer are: multilayer blocks of controllers of the rectifier part and the inverter part as well as the master LCC control block. The description of the SwePol Link model is given in [9-14].

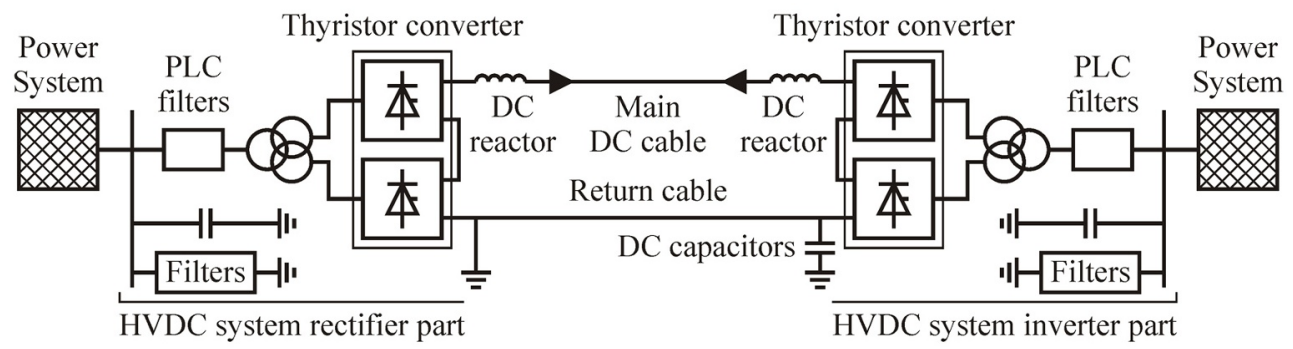

Fig. 3. Schematic diagram of the SwePol Link model for simulation research [10]. 
For the developed model, the LCC behavior tests were conducted during single-phase short-circuits and ARL in AC network lines. Parametric analysis was used for the research. The short-circuits in the AC network were mapped by changing the values of electrical quantities at the connection point of the LCC inverter station:

- the RMS voltage of the selected phase $(U)$;

- the phase angle of the voltage of the selected phase $(\varphi)$;

- short-circuit power $\left(S_{k Q}\right)$.

The research plan is presented in Table 1. The 4 simulation scenarios were identified, out of 12 prepared by the authors in [14]. The historical data recorded for the SwePol Link for multiple commutation failures were used to determine the change ranges of particular parameters. It was assumed that in the pre-interrupt state all parameters' values were equal to $1 \mathrm{pu}$ (for $U$ and $S_{k Q}$ ) or $0^{\circ}$ (for $\varphi$ ).

Table 1. Scenarios of LCC simulation tests.

\begin{tabular}{|c|c|c|c|}
\hline Scenario & $U(\mathrm{pu})$ & $\varphi\left(^{\circ}\right)$ & $S_{k O}(\mathrm{pu})$ \\
\hline 1 & 1.00 & 10 & 0.8 \\
\hline 2 & 0.80 & 0 & 0.5 \\
\hline 3 & 0.80 & -25 & 1.0 \\
\hline 4 & 0.65 & 0 & 0.5 \\
\hline
\end{tabular}

The simulation results clearly indicate that single-phase short-circuits and ARL in AC network lines may prevent correct commutation in the LCC. The disturbance scenarios in the AC network are subject to high variability of operating conditions of both LCC and AC networks. This is shown in Figure 4 for the LCC.

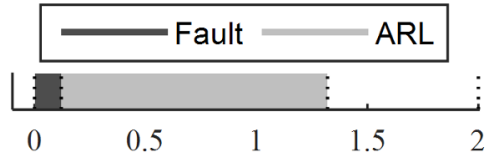

Scenario 1
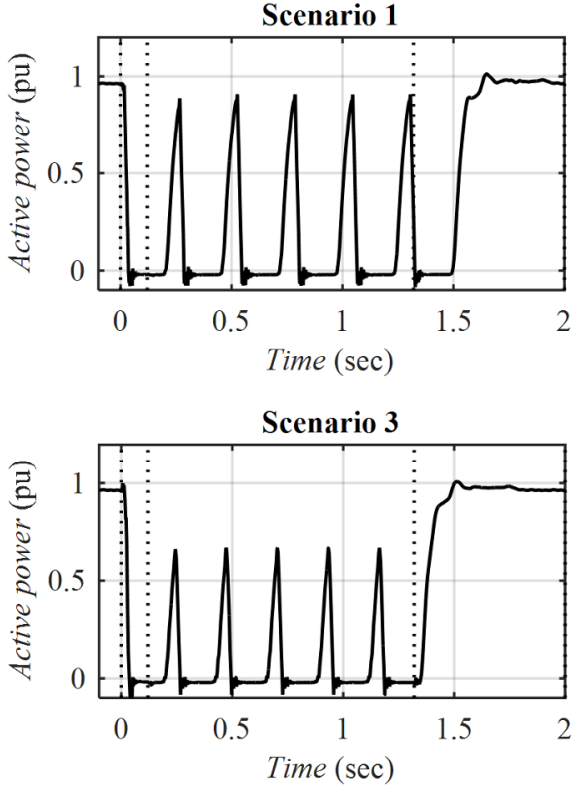

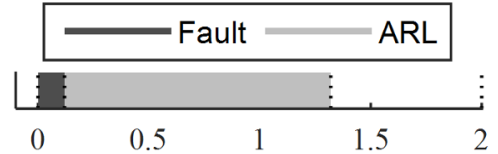

Scenario 2
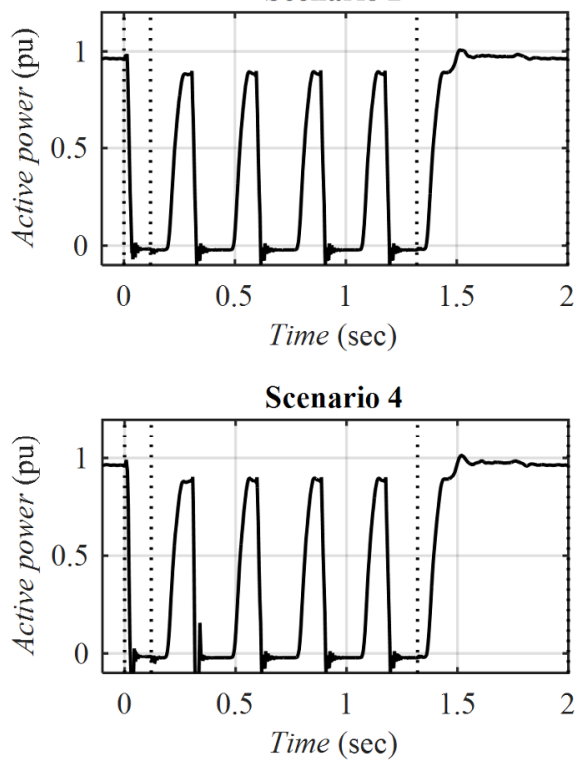

Fig. 4. Power transmitted by the LCC during a short-circuit in the AC network, for different simulation scenarios. 
Commutation failures in the LCC during the shortcut scenarios in the AC network under consideration cause rapid changes in the active power values transmitted by the LCC. The average power transmitted by the LCC during a short-circuit in the AC network is small and ranges from $0.09 \mathrm{pu}$ (for Scenario 3 ) to $0.24 \mathrm{pu}$ (for Scenario 2); before the shortcircuit occurrence the model was set to $1 \mathrm{pu}$. There are also short periods of time without power exchange between the LCC and the PS. However, if LCC blocking is used in accordance with the NC HVDC, then the LCC would not transmit power at all during a short-circuit in the AC network. For the simulation scenarios considered, the break takes 1.32 seconds. It consists of 0.12 seconds needed to clear the short-circuit by Power Protection and a 1.2 second break ARL (these are typical values for the High Voltage network in the Polish PS).

Blocking power transmission by the LCC may adversely affect operating conditions in the PS. Among the parameters' values that will change are among other the power flow in the PS, voltage distribution, generator and control system operating points, etc. Therefore, the authors have developed an alternative. It is proposed to temporarily limit the level of power transmitted by LCC $[9,10,14]$.

\section{Analysis of the effectiveness of temporary LCC power limitation during short-circuits in the AC network}

Temporary limitation of the LCC power during short-circuits in the AC network consists in reducing the set of the LCC power level. This action should be taken immediately after the occurrence of single-phase short-circuit and ARL in the AC network lines. After a specified time (equal to at least the ARL break) the set LCC power level can be automatically restored to pre-fault value. This should be done with a gradient acceptable for a given LCC. The possible course of LCC power limitation is shown in Figure 5.

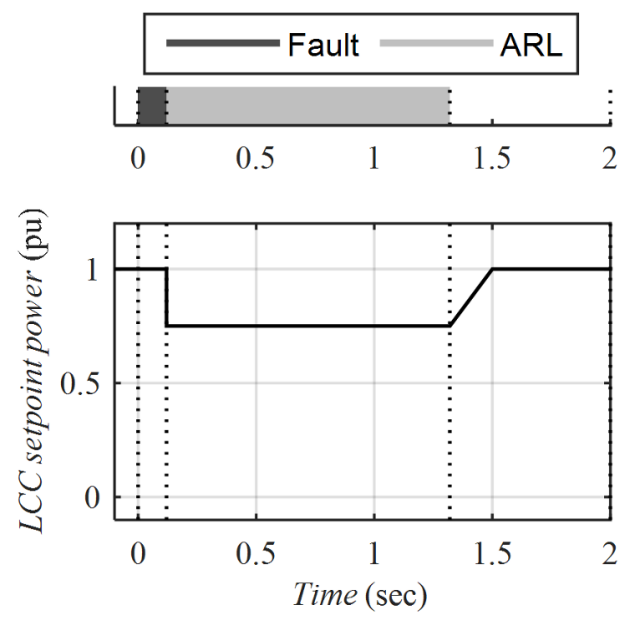

Fig. 5. Exemplary limitation of the LCC power during a short-circuit in an AC network.

The effectiveness of the authors' proposals was verified using simulations for the scenarios from Table 1. Three possible degrees of the LCC power reduction were deterministically assumed $(0.75 \mathrm{pu}, 0.50 \mathrm{pu}$ and $0.25 \mathrm{pu}$, in relation to the preset level in the pre-fault state). The simulation results confirm that by temporarily limiting the LCC power, the LCC operating conditions significantly improved during short-circuits in the AC network. For most scenarios, a small reduction in LCC power was sufficient. This is presented in Table 2. As the "Yes" situations were marked when there were no commutation failures in the LCC after applying a temporary limit of LCC power. 
Table 2. Improvement of the LCC operating conditions after limiting the LCC power during the short-circuit in the AC network.

\begin{tabular}{|c|c|c|c|c|}
\hline \multirow{2}{*}{$\begin{array}{c}\text { LCC setpoint } \\
\text { power }(\mathrm{pu})\end{array}$} & \multicolumn{4}{|c|}{ Scenario } \\
\cline { 2 - 5 } & 1 & 2 & 3 & 4 \\
\hline $1.00 \rightarrow 0.75$ & No & Yes & No & Yes \\
\hline $1.00 \rightarrow 0.50$ & Yes & Yes & No & Yes \\
\hline $1.00 \rightarrow 0.25$ & Yes & Yes & Yes & Yes \\
\hline
\end{tabular}

The improvement of the LCC operating conditions is also shown in Figure 6, for Scenario 4. Previously, there were multiple commutation failures in the LCC, after singlephase short-circuiting and ARL in the AC network line (see Fig. 6a). On the other hand, due to the temporary limited power of the LCC, only one commutation change is observed (see Fig. 6b). This is harmless and does not require disabling the LCC. This failure is caused by a short-circuit in the AC network line. However, during the ARL there were no commutation problems in the LCC. Thanks to this, there is no risk of destabilizing the PS operation. Previously, there was such a risk. The limitation of LCC power allows avoiding such dangerous situations.

An additional benefit of the authors' proposal is the continuous transmission of power by the LCC during the ARL. Power peaks were previously observed (see Fig. 6a) or no power transfer (when the LCC is blocked, according to the NC HVDC). After applying the authors' proposal, the average power transmitted by LCC during a short-circuit in the AC network increased by as much as 2.6 times, for the short-circuit Scenario 4 in the AC network. Moreover, such a large increase is possible even though the LCC power has been temporarily limited from 1 pu to 0.75 pu (see Fig. 6b).

a)
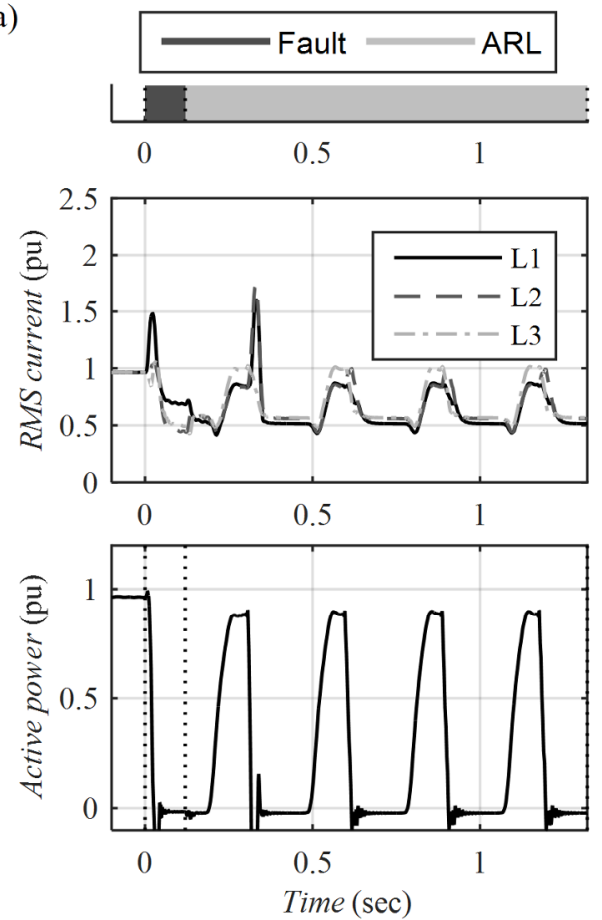

b)
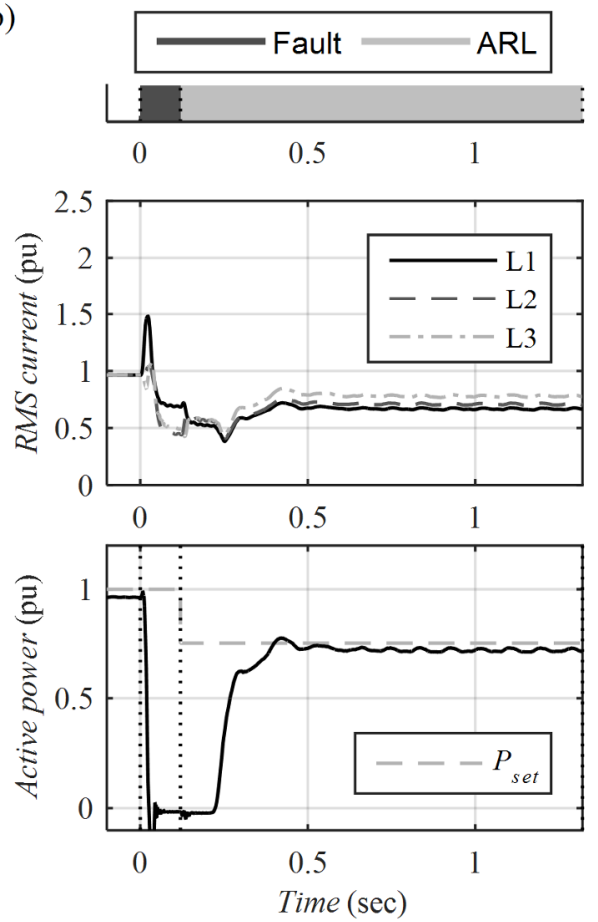

Fig. 6. The current in the inverter station and the power transmitted by the LCC during short-circuit in the AC network, for Scenario 4: a) without limiting the LCC power; b) with limiting the LCC power to $0.75 \mathrm{pu}\left(P_{\text {set }}\right)$. 


\section{The concept of the LCC power limiting system during short- circuits in the AC network}

It has been shown that the temporary limitation of the LCC power during short-circuits in the $\mathrm{AC}$ network is an effective remedy. It allows to eliminate dangerous multiple commutation failures during single-phase short-circuits and ARL in AC network lines. Therefore, the authors have developed an automation system that will implement their idea. The automation system proposed by the authors was called Area-System Detection of Automatic Reclosing Line (ADAR). The logic diagram of the ADAR operation is shown in Table 3.

Table 3. Basic ADAR tasks.

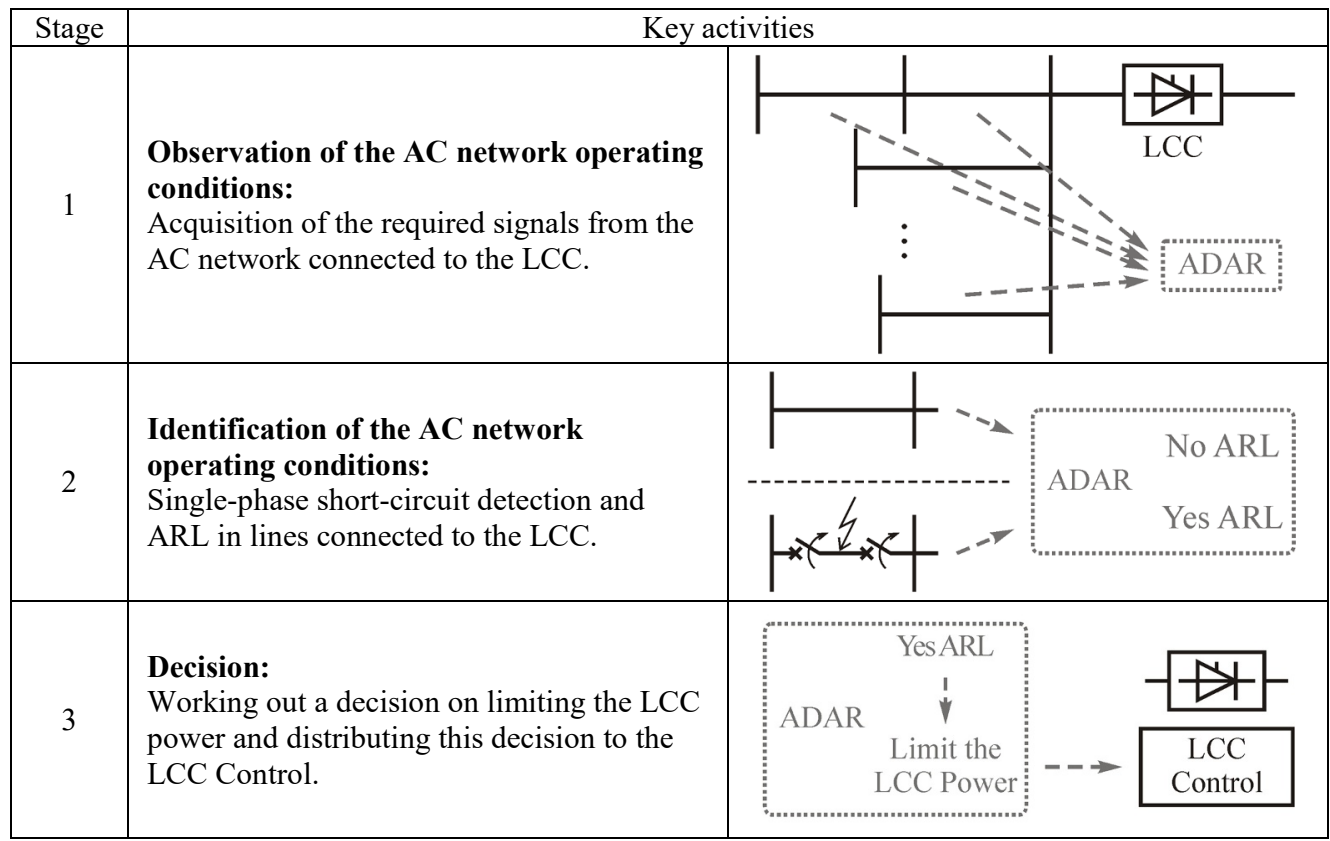

In ADAR, the decision to limit the LCC power can be made in two ways:

- Algorithm I: deterministic limitation of the LCC power to one level, regardless of current short-circuit conditions of the AC network operation;

For this ADAR operation method, one level of the LCC power reduction is determined. This should ensure the absence of multiple commutation failures in the LCC for all (or almost all) short-circuits in the AC network. An advantage of this solution is the simple ADAR decision algorithm (see Fig. 7). The second advantage is the small set of ADAR input signals. It is enough to provide a signal that the protection in the AC network is activated, the signal that switches off the AC circuit breakers or the ARL start signal. However, the disadvantage may be too restrictive limitation of the LCC power.

or

Power Protection activation signal in AC network

or

\section{Power Protection signals in AC network}

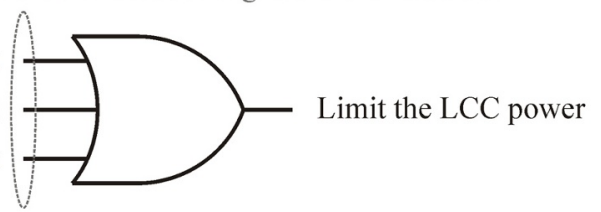

Fig. 7. Block diagram of the first ADAR decision algorithm. 
- Algorithm II: adaptive limitation of the LCC power to the level dependent on the current short-circuit conditions of the AC network operation.

For this ADAR operation mode in order to determine the LCC power reduction level it is required to know what are the current operating conditions of the AC network during a short-circuit. The authors' research in [9-14] indicate that for most cases it is sufficient to control the voltage value at the point of connection, the phase angle of this voltage and the value short-circuit power. The information about the current value and phase angle of the voltage will provide an access to the voltage transformers at the LCC connection point. However, the current level of the short-circuit power can be determined based on the current topology of the AC network. This can be done using a formerly prepared tabular summary that covers all possible topologies of an AC network connected to the LCC. The disadvantage of this solution is the complex ADAR decision algorithm (see Fig. 8). However, this will allow adjusting the LCC power reduction scale to the current conditions of a short-circuit in the AC network.

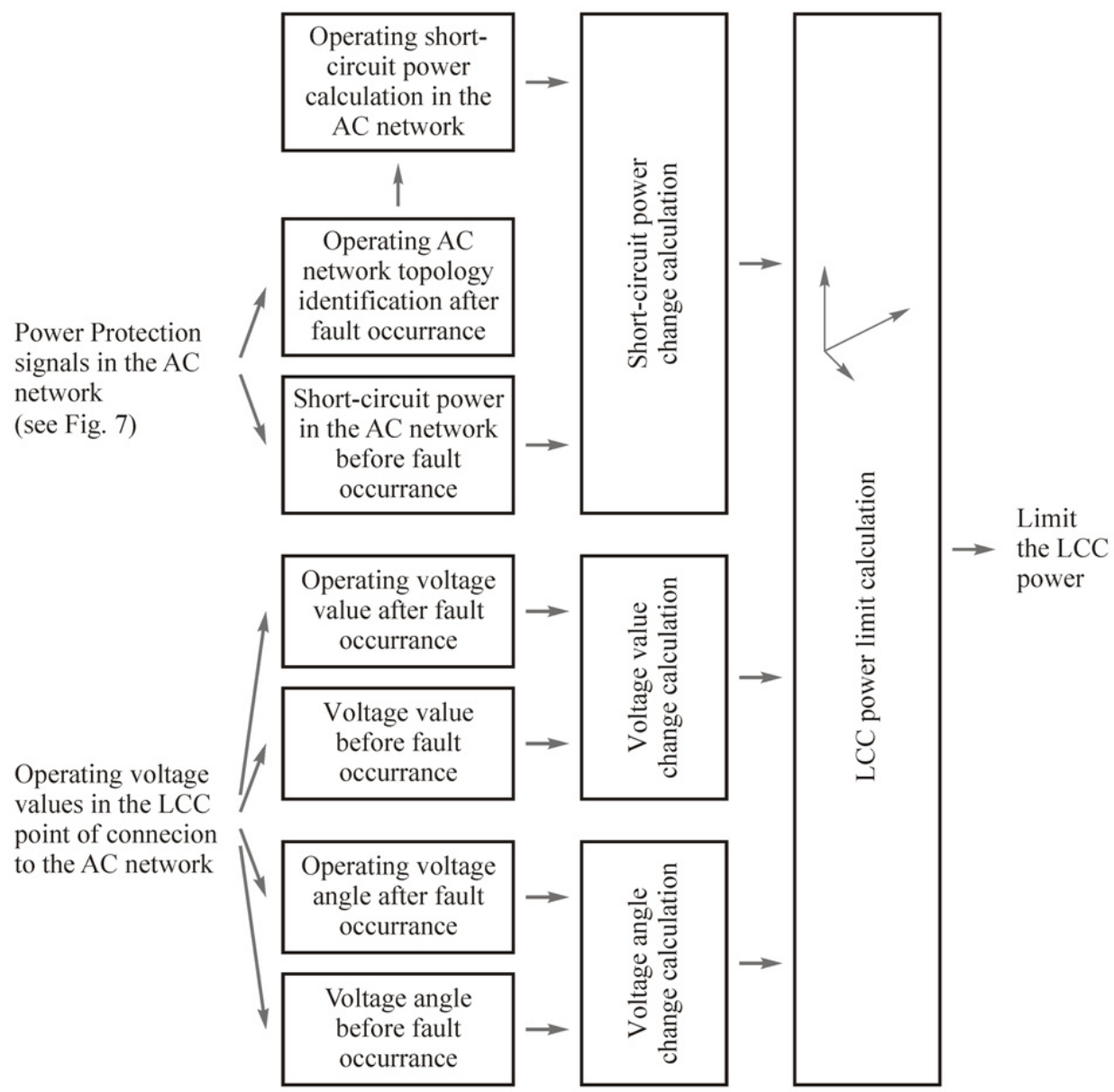

Fig. 8. Block diagram of the second ADAR decision algorithm.

It is possible to use the ADAR functionality to implement multi-agent systems of area power automation. It is predicted that it will significantly increase the correctness of the AC network status identification. An exemplary structure of an agent of such a system is defined and described in [15]. 


\section{Summary}

It is reasonable and necessary to implement remedial measures limiting commutation problems in the LCC during short-circuits in the AC network. Abnormal conditions of an AC network operation should not lead to LCC switching off. One of the countermeasures may be blocking the LCC during a short-circuit in the AC network. The application of this solution is allowed by the HVDC dedicated network code. However, a better solution is to temporarily limit the LCC power during a short-circuit in the AC network. Simulation verification of the authors' idea proved its effectiveness. A significant improvement in LCC working conditions was achieved.

It is emphasized that this is a remedy that does not require interference in the physical layer of the LCC. Thus, its application in existing LCCs is possible. It is noted that in practice it is not possible to completely eliminate switching problems in the LCC. However, it is possible to significantly improve the LCC operating conditions by limiting them, and in particular by minimizing dangerous multiple commutation failures, which force the LCC to be switched off and the power exchange between LCC and the PS to be interrupted.

Other possible remedies for the LCC are presented in $[2,7,10,11]$, including the authors' ideas.

\section{References}

1. Commission Regulation (EU) 2016/1447 of 26 August 2016 establishing a network code on requirements for grid connection of high voltage direct current systems and direct current-connected power park modules

2. M. Szablicki, P. Rzepka, R. Czapaj i inni, Development of general use requirements for high voltage direct current systems and direct current-connected power park modules in accordance with the Commission Regulation (EU) 2016/1447 of 26 August 2016 (Opracowanie wymogów ogólnego stosowania systemów wysokiego napięcia prądu stałego oraz modułów parku energii z podłączeniem prądu stałego w zakresie wynikającym z zapisów Rozporządzenia Komisji (UE) 2016/1447 z dnia 26 sierpnia 2016 r.), zlecenie dla PSE S.A., Katowice (2017 i 2018)

3. G.P. Adam, K.H. Ahmed, S.J. Finney, B.W.Williams, AC Fault Ride-Through Capability of a VSC-HVDC Transmission Systems, 2010 IEEE Energy Conversion Congress and Exposition (2010)

4. I. Erlich, Ch. Feltes, F. Shewarega, Enhanced Voltage Drop Control by VSC-HVDC Systems for Improving Wind Farm Fault Ridethrough Capability, IEEE Transactions On Power Delivery, 29 (2014)

5. A. Beddard, M. Barnes, AC Fault Ride-through of MMC VSC-HVDC Systems, $7^{\text {th }}$ IET International Conference on Power Electronics, Machines and Drives (2014)

6. J. Maniero, S. Tennakon, C. Barker, F. Hassan, Energy Diverting Converter Topologies for HVDC Transmission Systems, $15^{\text {th }}$ IEEE European Conference Power Electronics and Applications (2013)

7. J. Ivarsson, Improvement of Commutation Failure Prediction in HVDC Classic Links. Electrical Engineering, Bachelor's Thesis (2011)

8. M. Khatir, S.A. Zidi, M.K. Fellah, S. Hadjeri, M Flitti, The Impact Study of a Statcom on Commutation Failures in an HVDC Inverter Feeding a Weak AC System, Journal of Electrical Engineering, 60 (2012) 
9. M. Przygrodzki, P. Rzepka, M. Szablicki, Analysis of the AC Polish Power System impact on the HVDC SwePol Link operation, International Symposium CIGRE 2015 Across borders - HVDC systems and market integration (2015)

10. M. Szablicki, M. Przygrodzki, P. Rzepka, Simulation analysis of the effectiveness of measures mnimizing the risk of commutation failures in LCC HVDC systems (Symulacyjna analiza skuteczności środków minimalizujących ryzyko błędów komutacji w łączach HVDC wykonanych w technologii LCC), unpublished (2016)

11. M. Przygrodzki, P. Rzepka, M. Szablicki, Analysis of opportunities to improve the HVDC SwePol Link operation due to commutation failures, CIGRE Session 46 (2016)

12. M. Przygrodzki, P. Rzepka, M. Szablicki, Power Network Operating Conditions vs HVDC SwePol Link Operation (Warunki pracy otoczenia sieciowego a praca łącza HVDC SwePol Link), Zeszyty Naukowe Wydziatu Elektrotechniki i Automatyki Politechniki Gdańskiej, 45 (2015)

13. M. Przygrodzki, P. Rzepka, M. Szablicki, Influence of Power System on Operation of an HVDC Link. A Case Study, Acta Energetica, 26 (2016)

14. M. Przygrodzki, P. Rzepka, M. Szablicki, Limitation of multiple commutation failures in HVDC systems during single-phase Automatic Reclosing (Ograniczenie wielokrotnych przewrotów w łączach HVDC podczas SPZ 1-fazowych), Chapter in the monograph from the series of the Automation Electricity Disturbances: Innovations and problems in high voltage electrical power engineering (Rozdział $\mathrm{w}$ monografii $\mathrm{z}$ serii Automatyka Elektryka Zakłócenia: Innowacje i problemy $w$ elektroenergetyce wysokich napięć) (2016)

15. A. Halinka, P. Rzepka, M. Szablicki, Agent Model of Multi-Agent System of Area Power System Protection, 2015 Modern Electric Power Systems (MEPS), 4 (2015) 